\section{DETERMINANTS OF LIVING ARRANGEMENTS FOR ELDERS TRANSITIONING FROM A NURSING HOME INTO THE COMMUNITY}

C. Fabius, J.T. Robison, University of Connecticut, Farmington, Connecticut

The Money Follows the Person (MFP) Demonstration allows nursing facility residents to transition into community living arrangements. Research has shown racial differences in living arrangements - Blacks are more likely than Whites to live in multigenerational households. Transitioning into the community may also be accompanied by challenges (i.e. lack of housing). This study examines the influence of race, choice, and transition challenges on living arrangements in $N=659$ ( $n=495,75 \%$ White, $n=164,25 \%$ Black) older (aged $65+)$ MFP participants in Connecticut. Multinomial and binomial regression models predicted living arrangements in unmarried and married participants. Findings show that among unmarried participants, Blacks are more likely to live alone or with family, and Whites are more likely to live with a live-in caregiver/supervised housing. White participants were also more likely to report having helped choose their home. Women and participants with more functional needs are more likely to live with family as well as with a live-in caregiver/supervised housing compared to those living alone. Having service challenges was a negative predictor of living with family, and having financial challenges was a negative predictor of living with a live-in caregiver/supervised housing compared to living alone. Among married participants, having more functional needs predicts living with a spouse, while those with housing challenges are less likely to live with a spouse. Research should further explore the impact of transition challenges on rebalancing programs. Findings can influence community housing plans and inform the field of gerontology with respect to cultural patterns in housing and service use.

\section{MEDICAID BENEFICIARIES' ACCESS TO RESIDENTIAL CARE SETTINGS}

M. Lepore, M. Knowles, K. Porter, J.M. Wiener, RTI

International, Washington, District of Columbia

Residential care settings (RCSs) are community-based housing and supportive services providers. Many RCSs predominantly serve older adults and younger people with physical disabilities. Medicaid beneficiaries' access to these RCSs is of concern to policymakers and other stakeholders because providing community-based-rather than institutional-services is potentially less expensive and preferred by most people. To better understand Medicaid beneficiaries' access to RCSs that focus on older adults and young people with physical disabilities, we examined Medicaid policies in 50 states and the District of Columbia, interviewed subject matter experts $(n=7)$, and conducted four state case studies informed by reviews of policies and interviews with stakeholders $(\mathrm{n}=27)$. Interviewees identified numerous factors influencing Medicaid beneficiaries' access to these RCSs, including the supply of Medicaid-certified RCSs relative to the older adult population, Medicaid reimbursement rates, initiatives that affect room and board costs for Medicaid beneficiaries, and policies that may incentivize RCSs to serve Medicaid beneficiaries. These factors can affect Medicaid beneficiaries' access to RCSs by limiting the number of RCSs that participate in Medicaid, restricting the number of beds that RCSs allot to Medicaid beneficiaries, and by determining whether room and board rates will be affordable for Medicaid beneficiaries. The implications of these findings vis-à-vis implementation of federal Medicaid home and community-based services rules and continued implementation of managed long-term services and supports programs are discussed.

\section{ANTIPSYCHOTIC AND RESTRAINT USE AMONG LONG-STAY NH RESIDENTS: IMPACT OF CMS REGULATORY CHANGES \\ J.A. Lucas ${ }^{1}$, J.R. Bowblis ${ }^{2}$, 1. Seton Hall University, South Orange, New Jersey, 2. Miami University, Oxford, Obio}

APMs have potential for adverse effects and mortality risk for $\mathrm{NH}$ residents with dementia. CMS initiated its "National Partnership" (March 2012) to reduce APM use, implemented public reporting an APM quality measure (July 2012), and revised NH surveyor guidelines and training to identify unnecessary APMs and compliance with new dementia care standards (May 2013). We determine NH response to these initiatives, by examining change in APM and physical restraint utilization among long-stay $\mathrm{NH}$ residents and whether these vary with resident cognitive functioning. Using data from 2011-2013 Minimum Data Set, we examined long-stay residents in free-standing facilities that did not have CMS-approved indications for APM ( $\mathrm{N} \approx 8$ million). Linear probability models controlled for resident and facility characteristics and determined how restraint and APM rates change in response to each CMS initiative. Results were stratified into groups: no dementia/mental illness, dementia without symptoms (i.e., behavioral symptoms, delusions/hallucinations), dementia with symptoms, and severe mental illness consistent with APM utilization (e.g., bipolar, psychosis, and severe depression). Pre-initiative physical restraint use averaged $2.5 \%$, with rates higher among those with dementia and severe mental illness. Among all groups, restraint use declined with each initiative. Pre-initiative APM use averaged $23.2 \%$, though rates varied significantly with cognitive functioning $(7.0 \%-66.2 \%)$. All groups saw declines in APM use with each CMS initiative; largest decline was among dementia residents without symptoms $(27.8 \%)$, smallest among residents with mental illness $(9.7 \%)$. Regulatory efforts to reduce APM prescribing had a significant impact, without an increase in physical restraint use; effectiveness varies with resident cognitive functioning.

\section{DETERMINING HOME AND COMMUNITY-BASED SERVICE USE AMONG OLDER MONEY FOLLOWS THE PERSON PARTICIPANTS}

\section{Fabius, J.T. Robison, University of Connecticut,} Farmington, Connecticut

The use of home and community-based services (HCBS) has been examined in research on community-dwelling elders. Research has not yet investigated the determinants of HCBS use among elders participating in a nursing facility transition program such as the Money Follows the Person (MFP) Rebalancing Demonstration. Further, race may be a factor in HCBS use - previous findings in communitydwelling populations have been mixed. The current study utilized The Andersen Behavioral Model of Health Service 